\title{
The role of patient's profile and allogeneic blood transfusion in development of post-cardiac surgery infections: a retrospective study
}

\author{
Nousjka P.A. Vranken ${ }^{a}$, Patrick W. Weerwind ${ }^{a, *}$, Paul J.C. Barenbrug ${ }^{a}$, Steven Teerenstra ${ }^{b}$, \\ Yuri M. Ganushchak and Jos G. Maessen ${ }^{\mathrm{a}}$
}

a Department of Cardiothoracic Surgery, Maastricht University Medical Centre and Cardiovascular Research Institute Maastricht, Maastricht, Netherlands
b Department for Health Evidence, Section Biostatistics, Radboud University Medical Centre, Nijmegen, Netherlands
* Corresponding author. Maastricht University Medical Centre, PO Box 5800, 6202 AZ Maastricht, Netherlands. Tel: +31-43-3875070; fax: +31-43-3875075;
e-mail: p.weerwind@maastrichtuniversity.nl (P.W. Weerwind).

Received 25 November 2013; received in revised form 6 March 2014; accepted 11 March 2014

\begin{abstract}
OBJECTIVES: We aimed to investigate the association of patient characteristics and allogeneic blood transfusion products in development of post-cardiac surgery nosocomial infections.
\end{abstract}

METHODS: This retrospective study was conducted in 7888 patients undergoing cardiac surgery with median sternotomy and cardiopulmonary bypass. Multivariable logistic regression analysis was used for independent effect of variables on infections.

RESULTS: A total of 970 (12.3\%) patients developed one or several types of postoperative infections. Urinary $(n=351,4.4 \%)$ and pulmonary tract infections ( $n=478,6.1 \%$ ) occurred more frequently than sternal wound infections (superficial: $n=102,1.3 \%$, deep: $n=72,0.9 \%)$ and donor site infections $(n=61,0.8 \%)$. Interventions, including valve replacement $(P=0.002)$ and coronary artery bypass grafting combined with valve replacement $(P=0.012)$, were associated with increased risk of several types of postoperative infections. Patients' profiles changed substantially over the years; morbid obesity $(P=0.019)$, smoking $(P=0.001)$ and diabetes mellitus $(P=0.001)$ occur more frequently nowadays. Furthermore, surgical site infections showed to be related to morbid obesity $(P<0.001)$ and higher risk stratification $(P=0.031)$. Smoking $(P<0.001)$ and chronic obstructive pulmonary disease $(P<0.001)$ were related to pulmonary tract infections. In addition, diabetic patients developed more sepsis $(P=0.003)$ and advanced age was associated with development of urinary tract infections $(P<0.001)$. Even after correcting for other factors, blood transfusion was associated with all types of postoperative infection $(P<0.001)$. This effect remained present in both leucocyte-depleted and non-leucocyte-depleted transfusion.

CONCLUSIONS: Our data showed that post-cardiac surgery infections occur more frequently in patients with predetermined risk factors. The amount of blood transfusions was integrally related to every type of postoperative infection.

Keywords: Nosocomial infection • Patient characteristics • Blood transfusion • Cardiopulmonary bypass

\section{INTRODUCTION}

Infections following cardiac surgery remain a major burden for patients' morbidity, causing prolonged hospital stay, and thereby higher health-care costs $[1,2]$. Reported incidence rates of nosocomial infections vary from 5 to $21 \%$ in patients undergoing cardiac surgery using cardiopulmonary bypass (CPB) [3]. In general, these infections are conjectured to be related to contamination and tissue traumatization during coronary artery bypass grafting (CABG) surgery, whereas host resistance compromised by the severity of the underlying disease appears to be more important during cardiac valve surgery [4]. Moreover, allogeneic blood transfusion, although considered safe, has shown to play a pivotal role in the development of postoperative infections mediated through immunosuppression [5-7]. Several studies report blood transfusion to have negative effects on patients' health, but contradictions about this statement remain present $[8,9]$. Furthermore, previous studies show that patient-related factors (age, gender, diabetes mellitus and reduced left ventricle ejection fraction) and duration of CPB are associated with an increase in development of infections after cardiac surgical interventions $[3,10]$.

Generally, the statistical power of many studies is adequate for investigation of one or two infection types, while the sample size may be not be sufficient to investigate multiple types of infection. Moreover, the focus is often on a particular type of infection, and not all possible related factors are included. On the other hand, the cardiac surgical patient population has changed substantially over the past years. Patients undergoing CABG surgery nowadays are older, more likely to be of female gender and of higher risk for multiple postoperative complications compared with the population a decade ago [11]. This change in patient profiles implies that risk factors determined in previous studies are not transferable to the current clinical practice.

The aim of this study was to determine the incidence of postoperative nosocomial infections and secondly, to investigate the contribution of blood transfusion (leucocyte-depleted 
or non-leucocyte-depleted packed red blood cells) in the development of postoperative cardiac surgery infections during a 10-year time span.

\section{MATERIALS AND METHODS}

\section{Patient population}

This retrospective study included all adult patients who underwent median sternotomy during a cardiac surgical intervention using CPB between the years 1997 and 2006. Institutional approval was granted based on a retrospective quality analysis of our patient surgery database. Immediately after surgery, patients were admitted to the cardiac intensive care unit. Urine catheters were removed on the second day postoperatively. Exclusion criteria were death in the operating room or within 30 days postoperatively, off-pump procedure and heart transplant. As a consequence of CABG (with or without valve surgery), patients can potentially develop a donor site infection (DSI). Data of these patients were taken into analysis separately to determine the incidence and risk factors associated.

\section{Study design and data collection}

The database of the Department of Cardiothoracic Surgery was analysed to specifically obtain patient data for postoperative nosocomial infections. After data collection, data cleaning and applying exclusion criteria, 7888 patients remained for analysis.

Patients' characteristics and information on the use of blood transfusion products were matched with patient data, surgery data and postoperative data. Infectious complications occurring after surgery were registered and adopted as a postoperative nosocomial infection. In this study, a total of 34 intraoperative variables were taken into account, including patient-related data, surgeryrelated factors, European system for cardiac operative risk evaluation (EuroSCORE) and perioperative factors (Table 1) [12].

In the year 2002, a national transition to leucocyte-depleted blood has taken place. To investigate whether this causes a change in the role of blood transfusion and postoperative infections, the entire patient population was split into a section before and after 2002.

\section{Definitions}

Wound infections were defined according to the 1992 modified definitions for wound infection of the Centres for Disease Control and Prevention [13]. Blood stream and urinary tract infections were diagnosed by at least one positive culture. Diagnosis of pulmonary tract infection was conducted by detecting increased body temperature $\left(>37.5^{\circ} \mathrm{C}\right)$, pulmonary acoustics and a positive sputum culture detection.

\section{Statistical analysis}

Statistical analysis was performed using Statistical Package for the Social Sciences (SPSS Inc., Chicago, IL, USA). Numeric variables were expressed as mean \pm standard deviation or as median (interquartile range), depending on the data distribution assessed by
Table 1: Preoperative, postoperative and perioperative variables

Patient-related Gender, age, NYHA classification, morbid obesity, diabetes mellitus, peripheral vascular disease, hypertension, pulmonary hypertension, active endocarditis, smoking, hypercholesterolaemia, renal dysfunction, COPD, log EuroSCORE, LVEF, previous $\mathrm{MI}$, cerebrovascular disease ${ }^{\mathrm{a}}$, immunosuppressive treatment, antibiotics, inotropes, aspirin, $\beta$-blockers, nitrates, antiaggregant therapy, steroids, digitalis.

Surgery-related Type of surgery, reoperation, CPB time, aortic cross-clamping time, IABP, antiarrhythmics, antifibrinolytics.

Perioperative Total amount of packed red blood cell transfusions.

COPD: chronic obstructive pulmonary disease; CPB: cardiopulmonary bypass; EuroSCORE: European system for cardiac operative risk evaluation; IABP: intra-aortic balloon pump; LVEF: left ventricle ejection fraction; MI: myocardial infarct; NYHA: New York Heart Association.

${ }^{a}$ Cerebrovascular disease includes cerebral vascular accident, transient ischaemic attack, reversible ischaemic neurological deficit, subarachnoidal bleeding and epilepsy.

the Kolmogorov-Smirnov test and visualization with histograms. A $P$-value of $<0.05$ was considered significant.

Means from continuous variables were compared using student's $t$-test for independent samples. To identify the relation between each single risk factor and postoperative infections, univariate analysis was performed for every type of infection, which are superficial sternal wound infection (SSWI), deep sternal wound infection (DSWI), DSI, sepsis, urinary tract infection and pulmonary tract infection. For the comparison of dichotomous variables, the $\chi^{2}$ test was used. The Fisher's exact test was conducted when more than $20.0 \%$ of cells have an expected frequency $<5$.

As univariate analysis does not adjust for possible confounding of risk factors with each other, all variables were included in a multivariable logistic regression model using both stepwise backward and forward selection of variables (Wald method). Non-normally distributed continuous variables were log transformed before adding into multivariate analysis.

To assess the impact of different numbers of blood transfusions, the incidence rates of postoperative infection were analysed for $3-4,5-6,7-8,9-10$ and $>10$ transfusions compared with 1 or 2 transfusions.

Regarding the differences in risk of postoperative infections either before or after leucocyte depletion, odds ratios (ORs) were compared between two groups of patients. Since national transition to leucocyte-depleted red packed blood cells in 2002 was not thoroughly executed within a specified time span, patients operated on in that year were not included in this part of the analysis to minimize bias.

\section{RESULTS}

\section{Patients}

Of the 7888 patients, $30 \%(n=2374)$ were female. The patient population was divided into two groups (Table 2): patients with 
Table 2: Univariate analysis of categorical variables

\begin{tabular}{|c|c|c|}
\hline & $\begin{array}{l}\text { Infection group } \\
(n=970)\end{array}$ & $\begin{array}{l}\chi^{2} \text { test } \\
(P \text {-value })\end{array}$ \\
\hline \multicolumn{3}{|l|}{ Gender } \\
\hline Female & 334 (34.4\%) & 0.002 \\
\hline Male & $636(65.6 \%)$ & \\
\hline Smoking & $230(23.7 \%)$ & 0.431 \\
\hline Diabetes mellitus & $168(17.3 \%)$ & 0.213 \\
\hline Morbid obesity & 186 (19.2\%) & 0.091 \\
\hline Peripheral vascular disease & $64(6.6 \%)$ & 0.499 \\
\hline Hypertension & 379 (39.1\%) & 0.697 \\
\hline Pulmonary hypertension & $10(1.0 \%)$ & 0.071 \\
\hline Hypercholesterolaemia & $349(36.0 \%)$ & 0.001 \\
\hline Chronic renal failure & 65 (6.7\%) & 0.008 \\
\hline Active infected endocarditis & $2(0.2 \%)$ & 1.00 \\
\hline COPD & $116(12.0 \%)$ & $<0.001$ \\
\hline \multicolumn{3}{|l|}{ Preoperative medication } \\
\hline $\begin{array}{l}\text { Immunosuppressive } \\
\text { treatment }\end{array}$ & $5(0.5 \%)$ & 0.170 \\
\hline Digitalis & $46(4.7 \%)$ & $<0.001$ \\
\hline$\beta$-Blockers & 472 (48.7\%) & $<0.001$ \\
\hline ACE inhibitors & $246(25.4 \%)$ & 0.306 \\
\hline Nitrates-PO & $372(38.4 \%)$ & $<0.001$ \\
\hline Nitrates-IV & 34 (3.5\%) & 0.214 \\
\hline $\begin{array}{l}\text { Platelet aggregation } \\
\text { inhibitors }\end{array}$ & $86(8.9 \%)$ & 0.020 \\
\hline Anticoagulation & $70(7.2 \%)$ & 0.246 \\
\hline Inotropes & $7(0.7 \%)$ & 0.087 \\
\hline Heparin & $23(2.4 \%)$ & 0.186 \\
\hline Aspirin & $343(35.4 \%)$ & 0.002 \\
\hline NSAID & $15(1.5 \%)$ & 0.255 \\
\hline Corticosteroids & $27(2.8 \%)$ & 0.035 \\
\hline Antibiotics & $16(1.6 \%)$ & 0.809 \\
\hline Antacid & $39(4.0 \%)$ & 0.453 \\
\hline Cerebrovascular disease $\mathrm{a}^{\mathrm{a}}$ & $88(9.1 \%)$ & 0.001 \\
\hline \multicolumn{3}{|l|}{ NYHA-classification dyspnoea } \\
\hline I & $32(3.3 \%)$ & 0.012 \\
\hline II & 130 (13.4\%) & \\
\hline III & $204(21 \%)$ & \\
\hline IV & $38(3.9 \%)$ & \\
\hline Myocardial infarct & 290 (29.9\%) & 0.037 \\
\hline \multicolumn{3}{|l|}{ LVEF (\%) } \\
\hline$>50 \%$ & $843(9 \%)$ & 0.276 \\
\hline $30-50 \%$ & 104 (10.7\%) & \\
\hline$<30 \%$ & $23(2.4 \%)$ & \\
\hline Reoperation & 112 (11.5\%) & $<0.001$ \\
\hline Intra-aortic balloon pump & $121(12.5 \%)$ & $<0.001$ \\
\hline \multicolumn{3}{|l|}{ Surgery } \\
\hline CABG & 540 (55.7\%) & $<0.001$ \\
\hline CABG + valve replacement & $162(16.7 \%)$ & \\
\hline Valve replacement & 190 (19.6\%) & \\
\hline Other & $78(8.0 \%)$ & \\
\hline \multicolumn{3}{|l|}{ Medication at OR } \\
\hline Antifibrinolytics & 548 (56.5\%) & $<0.001$ \\
\hline Inotropes & $206(21.2 \%)$ & $<0.001$ \\
\hline Antiarrhythmics & $8(0.8 \%)$ & 0.002 \\
\hline \multicolumn{3}{|c|}{$\begin{array}{l}\text { CABG: coronary artery bypass grafting; COPD: chronic obstructive } \\
\text { pulmonary disease; LVEF: left ventricle ejection fraction; NSAID: } \\
\text { non-steroidal anti-inflammatory drugs; NYHA: New York Heart } \\
\text { Association; OR: operating room; ACE: angiotensin-converting enzyme. } \\
\text { acCerebrovascular disease includes cerebral vascular accident, transient } \\
\text { ischaemic attack, reversible ischaemic neurological deficit, } \\
\text { subarachnoidal bleeding and epilepsy. }\end{array}$} \\
\hline
\end{tabular}

postoperative infections $(n=970)$ and patients without postoperative infections $(n=6918)$. In the postoperative infection cohort, no methicillin-resistant Staphylococcus aureus-induced
Table 3: Changes in patient population before and after transition to leucocyte-depleted blood transfusion

\begin{tabular}{lccr} 
& $\begin{array}{l}\text { Before 2002 } \\
(n=4036)\end{array}$ & $\begin{array}{l}\text { After 2002 } \\
(n=3114)\end{array}$ & $P$-value \\
\hline Female gender & $1217(30.2 \%)$ & $936(30.1 \%)$ & 0.930 \\
Morbid obesity & $651(16.1 \%)$ & $568(18.2 \%)$ & 0.019 \\
Diabetes mellitus & $589(14.6 \%)$ & $545(17.5 \%)$ & 0.001 \\
Smoking & $952(23.6 \%)$ & $838(26.9 \%)$ & 0.001 \\
Log EuroSCORE $^{\mathrm{a}}$ & $1.0(1.2)$ & $1.1(1.3)$ & $<0.001$
\end{tabular}

EuroSCORE: European System for Cardiac Operative Risk Evaluation. ${ }^{a}$ Log EuroSCORE is depicted as median (interquartile range).

infection was observed. A total of 658 (8.7\%) were admitted for reoperative surgery. Surgical interventions included isolated CABG $(n=5364,68.0 \%)$, CABG combined with valve surgery $(n=800$, $10.1 \%)$, valve surgery alone $(n=1222,25.6 \%)$ and others such as intercardial or intervascular corrective surgery $(n=502,6.4 \%)$. A rate of $78.1 \%$ patients underwent CABG or CABG combined with valve surgery. This part of the patient population was used separately to further investigate DSIs.

A total of $5.6 \%(n=430)$ of all patients was supported with an intra-aortic balloon pump (IABP) perioperatively. A majority of patients $(n=6781,86 \%)$ received one or more homologous blood products.

Patients' profile change over the years. Comparing patients admitted for surgery before and after $2002(n=3114$ and $n=4036$, respectively), an increase was observed in the occurrence of morbid obesity, diabetes mellitus and smoking after 2002. The proportion of female patients did not change (Table 3 ).

\section{Incidence of infection}

In total, $970(12.3 \%)$ patients developed one or more infections, which lies within the reported range of $1.5-20 \%$. An incidence proportion of 478 (6.1\%) patients developed airway infection, 351 (4.4\%) urinary tract infection and $157(3 \%)$ one or several surgical site infections (SSI), including SSWI ( $n=102,1.3 \%)$, DSWI $(n=72$, $0.9 \%)$ and DSI ( $n=61,0.8 \%)$. One hundred and forty $(1.8 \%)$ patients developed sepsis and 54 (0.7\%) developed an unspecified type of postoperative infection. The total number of diagnosed postoperative infections in 970 patients was 1258. In total, $698(8.8 \%)$ patients had only one type of postoperative infection, while 272 patients (3.4\%) developed two or more separate types of infections. In Fig. 1, an overview is shown of each infection type and its contribution to the total number of postoperative infections.

\section{Mortality}

The mortality rate in the infected group was $2.7 \%$, which is significantly higher than the mortality incidence proportion of $0.7 \%$ in the non-infected group $(P<0.001)$. 


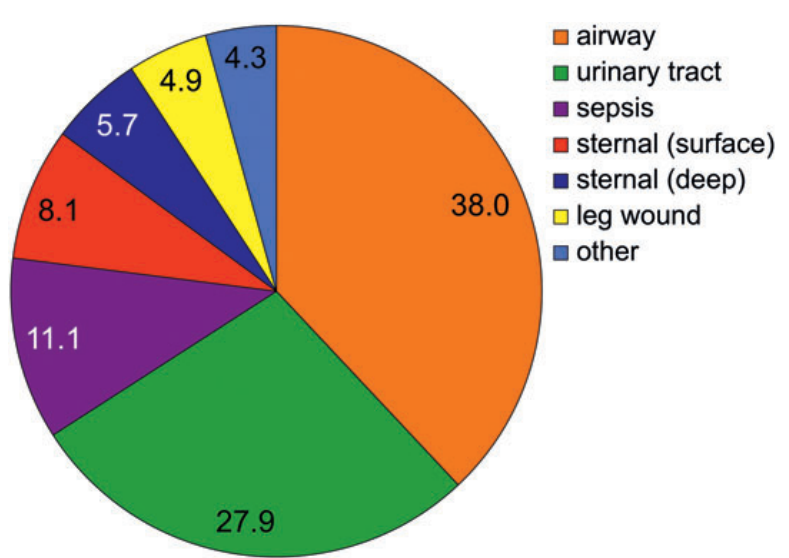

Figure 1: Frequency of different types of postoperative infections within total number of infections.

Table 4: Univariate analysis of numerical variables

\begin{tabular}{|c|c|c|}
\hline & $\begin{array}{l}\text { Infection group } \\
(n=970) \\
\text { Mean } \pm \mathrm{SD} / \\
\text { Median (IQR) }\end{array}$ & $\begin{array}{l}P \text {-value, independent } \\
\text { samples } t \text {-test/Mann- } \\
\text { Whitney U-test }\end{array}$ \\
\hline $\begin{array}{l}\text { Age (years at the date of } \\
\text { surgery) }\end{array}$ & $66.63 \pm 10.24$ & $<0.001$ \\
\hline $\mathrm{BMI}\left(\mathrm{kg} / \mathrm{m}^{2}\right)$ & $26.81(5.35)$ & 0.859 \\
\hline Logistic EuroSCORE (\%) & $3.70(4.51)$ & $<0.001$ \\
\hline CPB time (min) & $4.59(71.25)$ & $<0.001$ \\
\hline $\begin{array}{l}\text { Aorta-occlusion time } \\
\text { (min) }\end{array}$ & $4.10(50)$ & $<0.001$ \\
\hline $\begin{array}{l}\text { Erythrocyte blood } \\
\text { transfusion units } \\
\text { administrated } \\
\text { perioperatively }\end{array}$ & $4.00(5.0)$ & $<0.001$ \\
\hline
\end{tabular}

BMI: body mass index; CPB: cardiopulmonary bypass; EuroSCORE: European System for Cardiac Operative Risk Evaluation; SD: standard deviation; IQR: interquartile range.

\section{Univariate analysis}

Univariate analysis showed that patients with postoperative infections are significantly older $(P<0.001)$, and more likely to be female $(P=0.002)$. These group of patients also had more frequently dyspnoea (classification III or IV) $(P=0.012)$, chronic obstructive pulmonary disease (COPD) $(P<0.001)$, renal dysfunction $(P=0.008)$ and cerebrovascular disease $(P=0.001)$. Furthermore, these patients received more digitalis $(P<0.001)$ and corticosteroids preoperatively $(P=0.035)$, and received more blood transfusion products $(P<0.001)$. CBP time was significantly longer between patients who did and patients who did not develop any postoperative infection $(P<0.001)$ (Tables 2 and 4).

In Fig. 2, an overview is shown of the increase in infection incidence with increase in the number of transfusions (all groups compared with the group 1-2 transfusions). When patients received 5 or 6 transfusions, the incidence rate was significantly

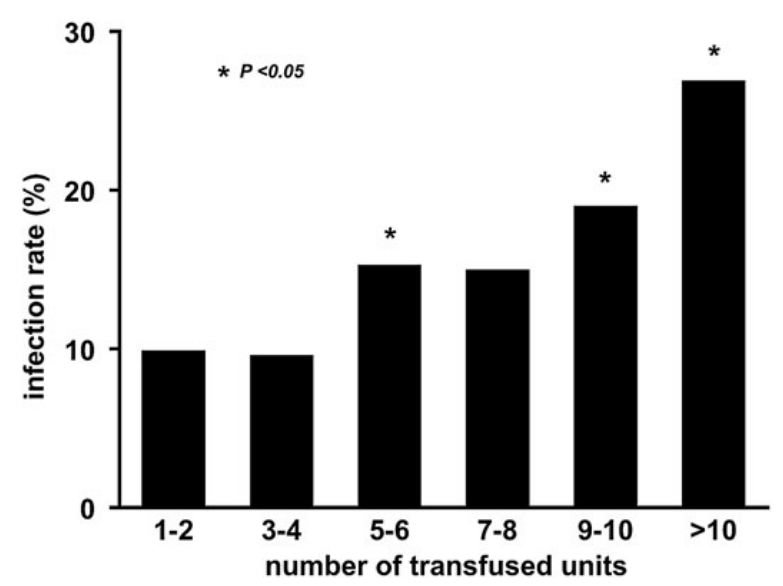

Figure 2: Infection rate compared with the number of allogeneic blood products transfused compared with 1-2 blood products.

higher compared with that in patients who received 1 or 2 transfusions. The infection incidence increased even further with a higher number of transfusions given, and even doubled at more than 10 transfusions.

\section{Multivariate regression analysis}

Outcomes of the forward (Wald statistic $P<0.05$ for inclusion) and backward (Wald statistic $P<0.10$ for exclusion) multivariable logistic regression analysis were mainly overlapping. Backward analysis selected two more variables than forward analysis, which were previous myocardial infarction and morbid obesity. The same analysis was performed for all specified infection types, shown in Table 5. The final model (infections in general) derived from the entire sample in forward multivariable logistic regression was composed of the following variables: type of surgery: valve replacement and valve replacement combined with CABG (respectively: $O R=1.355, P=0.002$ and $O R=1.343, P=0.012$ ); perfusion time $(O R=1.375, P=0.001)$; EuroSCORE $(O R=1.114, P=0.042)$; COPD $(O R=1.602, P<0.001)$; preoperative administration of digitalis $(O R=1.487, P=0.027)$; interoperative administration of antifibrinolytics $(O R=1.315, P<0.001)$ and inotropes $(O R=1.459$, $P<0.001)$; use of an IABP $(\mathrm{OR}=2.250, P<0.001)$; age $(\mathrm{OR}=1.011$, $P=0.010)$; body mass index $(\mathrm{OR}=1.794, P=0.001)$; cerebrovascular disease $(O R=1.363, P=0.016)$ and number of blood transfusions (OR $=1.326, P<0.001)$ (Table 6).

When considering the role of blood transfusion in the development of postoperative infection before and after 2002, the OR for the amount of blood transfusion units was slightly lowered after 2002. Analysis revealed ORs of 1.59 (infection in general, forward selection of variables, 95\% confidence interval (Cl) 1.32-1.93, $P<0.001)$ and 1.31 (95\% Cl 1.18-1.46, $P<0.001)$ for the cohort dating from 1997 to 2001 and 2003 to 2009, respectively.

\section{DISCUSSION}

Our study showed that at least one postoperative infection occurred in $12.3 \%$ of patients, which is in line with a previously reported range of 5-21\% [3]. Furthermore, post-cardiac surgery infections occur more frequently in patients with predetermined 
Table 5: Overview of variables associated with postoperative infections in forward multivariable logistic regression analysis

\begin{tabular}{|c|c|}
\hline $\begin{array}{l}\text { Type of } \\
\text { infection }\end{array}$ & Variables \\
\hline $\begin{array}{l}\text { Sternal } \\
\text { superficial }\end{array}$ & $\begin{array}{l}\text { Morbid obesity, CRF, inotropes, total amount of } \\
\text { blood products. }\end{array}$ \\
\hline Sternal deep & $\begin{array}{l}\text { Advanced age, higher BMI, smoking, diabetes } \\
\text { mellitus, cerebrovascular disease }{ }^{\mathrm{a}} \text {, Aspirin } \\
\text { preoperatively }{ }^{\mathrm{b}}, \mathrm{CABG}+\text { valve replacement or } \\
\text { isolated valve replacement surgery, total amount } \\
\text { of blood transfusions. }\end{array}$ \\
\hline Donor site & $\begin{array}{l}\text { Smoking, morbid obesity, CPB time, total amount of } \\
\text { blood products. }\end{array}$ \\
\hline Sepsis & $\begin{array}{l}\text { Smoking, diabetes mellitus, renal dysfunction, aspirin } \\
\text { preoperatively }{ }^{\mathrm{b}} \text {, EuroSCORE, IABP, surgery other } \\
\text { than isolated CABG, total amount of blood } \\
\text { transfusions. }\end{array}$ \\
\hline Urinary tract & $\begin{array}{l}\text { Female gender, advanced age, IABP, CPB time, } \\
\text { antifibrinolytics, surgery other than CABG and/or } \\
\text { valve surgery, total amount of blood products. }\end{array}$ \\
\hline $\begin{array}{l}\text { Pulmonary } \\
\text { tract }\end{array}$ & $\begin{array}{l}\text { Female gender, advanced age, smoking, COPD, } \\
\text { digitalis preoperatively, } \beta \text {-blockers preoperatively } \\
\text { cerebrovascular disease, IABP, reoperation, } \\
\text { prolonged CPB time, inotropes, total amount of } \\
\text { blood products. }\end{array}$ \\
\hline
\end{tabular}

BMI: body mass index; CABG: coronary artery bypass grafting; COPD: chronic obstructive pulmonary disease; CPB: cardiopulmonary bypass; CRF: chronic renal failure; EuroSCORE: European system for cardiac operative risk evaluation; IABP: intra-aortic balloon pump. ${ }^{a}$ Cerebrovascular disease includes cerebral vascular accident, transient ischaemic attack, reversible ischaemic neurological deficit, subarachnoidal bleeding and epilepsy.

bariable is negatively related to type of infection.

risk factors. Particularly, blood transfusion appeared to be a predominant factor in development of all types of postoperative infections. Another major finding was the change in patient risk profiles over time, and thus a change in risk for postoperative infections. A previous study by Ferguson et al. underlines the importance of monitoring patients' profiles over time in order to investigate the causes of postoperative complications, including infectious diseases [11].

In contrast to what one may expect, sternal wound infections were present in a much lesser extent. Two percent of all patients developed one or more SSI (mediastinitis and donor site), which was fairly low compared with the previously reported rates of 1.1$13.5 \%[6,14-16]$. This difference may be explained by the extent in sample size and/or focus of a single type of surgery in many studies. In addition, patient-related factors could also vary between the cohorts, as we found that patient-related factors such as smoking, obesity and diabetes mellitus were associated with surgical wound infections and sepsis. Other studies found the same association for the factors obesity and diabetes mellitus with SSI $[6,14]$. Additionally, a recent study by Lee et al. describes the relationship between COPD and SSI, which our results did not reflect. Further, respiratory and urinary tract infections occurred most frequently with a $6.1 \%$ rate of pulmonary tract infections, which again lies within the documented range of 1.2-6.5\% [10, 17]. Considering another risk factor, CPB duration was positively related to development of postoperative infection, as mentioned in several other studies $[3,18,19]$. Our results reflect this
Table 6: Overview of multivariable logistic regression analysis by forward selection of variables for infection in general

\begin{tabular}{|c|c|c|c|}
\hline $\begin{array}{l}\text { Any type of infection } \\
\text { Forward selection }\end{array}$ & $\begin{array}{l}\text { Odds } \\
\text { ratio }\end{array}$ & $95 \% \mathrm{Cl}$ & $P$-value \\
\hline \multicolumn{4}{|l|}{ Type of surgery* } \\
\hline CABG + valve replacement* & 1.343 & $1.066-1.692$ & 0.012 \\
\hline Valve replacement ${ }^{*}$ & 1.355 & $1.114-1.649$ & 0.002 \\
\hline Other & 1.060 & $0.790-1.422$ & 0.698 \\
\hline COPD & 1.602 & $1.279-2.007$ & 0.000 \\
\hline $\begin{array}{c}\text { Medication digitalis } \\
\text { preoperatively }\end{array}$ & 1.487 & $1.046-2.115$ & 0.027 \\
\hline Antifibrinolytics & 1.315 & $1.141-1.515$ & $<0.001$ \\
\hline Inotropes & 1.459 & $1.193-1.783$ & $<0.001$ \\
\hline Intra-aortic balloon pump & 2.250 & $1.755-2.883$ & $<0.001$ \\
\hline Age & 1.011 & $1.003-1.020$ & 0.010 \\
\hline CPB time (min) & 1.375 & $1.146-1.649$ & 0.001 \\
\hline Log EuroSCORE & 1.114 & $1.004-1.237$ & 0.042 \\
\hline Number of transfusion products & 1.326 & $1.200-1.466$ & $<0.001$ \\
\hline Body mass index & 1.794 & $1.271-2.532$ & 0.001 \\
\hline Cerebrovascular disease $^{a}$ & 1.363 & $1.059-1.753$ & 0.016 \\
\hline
\end{tabular}

CABG: coronary artery bypass grafting; $\mathrm{Cl}$ : confidence interval; COPD: chronic obstructive pulmonary disease; CPB: cardiopulmonary bypass; EuroSCORE: European system for cardiac operative risk evaluation.

${ }^{a}$ Cerebrovascular disease includes cerebral vascular accident, transient ischaemic attack, reversible ischaemic neurological deficit, subarachnoidal bleeding and epilepsy.

*Significance of type of surgery: $P=0.05$ (reference category: $C A B G$ ).

association for DSIs, urinary tract infection and pulmonary tract infection. Also, our results showed an association between female gender and advanced age and urinary and pulmonary tract infections, which is in part confirmed in a previous study conducted by Riera et al. [10]. Furthermore, our results showed a relationship between patient-related risk factors COPD and smoking and pulmonary tract infections, which is contradictive to Riera's findings. This may be explained by differences in inclusion and exclusion criteria compared with our study. Nonetheless, one of the risk factors found to be related to urinary tract infections was female gender, which confirms the findings of Kollef et al. [18].

We observed a change in patient-related risk factors as time progressed; patients more often become morbidly obese, diabetic and smoker and have a higher risk stratification score. As has been shown in our results and other studies, an increase in one or several of these risk factors causes an increase in the chances of postoperative infection occurrence.

On the other hand, blood transfusion was associated with a significantly increased risk in all infection types. Most importantly, this dose-dependent effect persisted when all other patient- and surgery-related risk factors and leucocyte depletion were included in analysis. The OR was slightly lowered after the implementation of leucocyte depletion; however, its impact remained present and statistically significant. New auto-transfusion techniques and bloodsparing developments, which play a pivotal role in cardiac surgery to this day, help the demand for transfusion products to slightly reduce over the years. However, blood transfusion remained independently associated with development of all types of postoperative infections.

The increase in susceptibility for postoperative infection in patients receiving red blood cell transfusions has been described previously in several studies $[3,6,15,17,20]$. One of these studies 
is a meta-analysis conducted by Hill et al., which provides evidence that allogeneic blood transfusion is related to a significantly increased risk of postoperative infections in surgical patients [20]. Contrastingly, some discrepancy remains in other studies, which may be due to differences in study population [8,9]. A commonly used explanation for this effect is the fact that, during blood transfusion, large amounts of foreign antigens are introduced to the recipients' circulation. This may result in immune down-regulation, which has been referred to as transfusion-associated immunomodulation (TRIM). It is still unknown which specific component(s) are responsible for the TRIM effect. However, a study conducted by Leal-Noval et al. shows that red blood cell transfusion mediates a shift in the balance between type 1 and type 2 CD4 T-helper cells [21]. This cell response, in combination with other cell responses, plays an important role in the immune reaction following cardiac surgery. Additionally, Vamvakas et al. reports that red blood cell transfusion might provoke a fall in lymphocyte count [22].

Leucocyte depletion by filtering of transfusion products has been nationally applied since 2002 to reduce human leucocyte antigen alloimmunization and transmission of cytomegalovirus in high-risk patients. The role of white blood cells in immunomodulatory transfusion effects is thought to be substantial and, therefore, leucocyte-depletion technology was expected to be of advantage to diminish infectious diseases. However, studies report contradictive results about whether leucocyte-depleted transfusions reduce the incidence of infectious complications or not [23-25]. One may speculate that blood transfusion continues to induce a greater risk of infections because other constituents than leucocytes are responsible for the TRIM effect. Additionally, transfusion of several units may overwhelm functions of the immune system, which causes bacterial clearance to be impaired.

Therefore, our data underlined the importance of diminishing the amount of blood transfusion administrations both during surgery and postoperatively. While time progresses, more patients are admitted for cardiac surgery with higher risk profiles compared with before. Every patient and procedure has its unique circumstances, which have to be taken into account before administering blood transfusion. It must be considered to what extent blood products will contribute to an improvement of patients' physical condition on the long term. Thus, re-examination of potential risks and benefits in every situation is a perquisite.

\section{STUDY LIMITATIONS}

For interpretation, it is a necessity to understand the possible factors of influence that are inherent to the observational study design, most importantly bias and confounding. Patients' and surgery data were retrieved based on standard protocols, and hence assessment bias is not likely for these variables. Physician's interpretation and opinions may have played a role in the detection and diagnosis of infections. Given the time span of the database and number of patients in the database, it is likely that numerous physicians were involved and, therefore, the results reflect an average over all kinds of assessment attitudes of physicians. In our opinion, this limits the influence of assessment bias. However, omittance of ventilation time data precluded analysis of factors related to development of pneumonia, which might be a contributing factor as has been recently described by Riera et al. [10]. Other factors that may be associated with infections but could not be investigated were surgical error, surgical complication and reopening for bleeding. As these are markers for complications, it would be expected that these would be implicitly captured by e.g. perfusion and aorta cross-clamping times, which were adjusted for in the analysis. By using multivariate regression, the risk of confounding is reduced; however, confounding by indication as well as confounding by unmeasured and/or unknown factors is as often difficult to exclude.

\section{CONCLUSION}

This study confirmed that predetermined risk factors are associated with a higher incidence of post-cardiac surgery infections and mortality. In particular, allogeneic blood transfusion showed to be an independent risk factor for postoperative infections, and therefore needs to be administered with caution.

\section{ACKNOWLEDGEMENTS}

We thank A.P. Simons for textual processing of the manuscript.

Conflict of interest: none declared.

\section{REFERENCES}

[1] Nosrati M, Boroumand M, Tahmasebi S, Sotoudeh M, Sheikhfathollahi M, Goodarzynejad $H$. Excess costs associated with common healthcareassociated infections in an Iranian cardiac surgical unit. J Hosp Infect 2010; 76:304-7.

[2] Graf K, Ott E, Vonberg RP, Kuehn C, Haverich A, Chaberny IF. Economic aspects of deep sternal wound infections. Eur J Cardiothorac Surg 2010; 37:893-6.

[3] Michalopoulos A, Geroulanos S, Rosmarakis ES, Falagas ME. Frequency, characteristics, and predictors of microbiologically documented nosocomial infections after cardiac surgery. Eur J Cardiothorac Surg 2006;29: 456-60.

[4] Miholic J, Hudec M, Domanig E, Hiertz H, Klepetko W, Lackner F et al. Risk factors for severe bacterial infections after valve replacement and aortocoronary bypass operations: analysis of 246 cases by logistic regression. Ann Thorac Surg 1985;40:224-8.

[5] Chelemer SB, Prato BS, Cox PM Jr, O'Connor GT, Morton JR. Association of bacterial infection and red blood cell transfusion after coronary artery bypass surgery. Ann Thorac Surg 2002;73:138-42.

[6] Loop FD, Lytle BW, Cosgrove DM, Mahfood S, McHenry MC, Goormastic $\mathrm{M}$ et al. J. Maxwell Chamberlain memorial paper. Sternal wound complications after isolated coronary artery bypass grafting: early and late mortality, morbidity, and cost of care. Ann Thorac Surg 1990;49:179-86; discussion 186-7.

[7] Murphy PJ, Connery C, Hicks GL Jr, Blumberg N. Homologous blood transfusion as a risk factor for postoperative infection after coronary artery bypass graft operations. J Thorac Cardiovasc Surg 1992;104:1092-9.

[8] Ali ZA, Lim E, Motalleb-Zadeh R, Ali AA, Callaghan CJ, Gerrard C et al. Allogenic blood transfusion does not predispose to infection after cardiac surgery. Ann Thorac Surg 2004;78:1542-6.

[9] Hughes MG, Evans HL, Lightfoot L, Chong TW, Smith RL, Raymond DP et al. Does prior transfusion worsen outcomes from infection in surgical patients? Surg Infect (Larchmt) 2003;4:335-43.

[10] Riera M, Ibanez J, Herrero J, Ignacio Sáez De Ibarra J, Enríquez F, Campillo $C$ et al. Respiratory tract infections after cardiac surgery: impact on hospital morbidity and mortality. J Cardiovasc Surg (Torino) 2010;51:907-14.

[11] Ferguson TB Jr, Hammill BG, Peterson ED, DeLong ER, Grover FL, Committee STSND. A decade of change-risk profiles and outcomes for isolated coronary artery bypass grafting procedures, 1990-1999: a report from the STS National Database Committee and the Duke Clinical Research Institute. Society of Thoracic Surgeons. Ann Thorac Surg 2002; 73:480-9; discussion 480-90.

[12] Choong CK, Sergeant P, Nashef SA, Smith JA, Bridgewater B. The EuroSCORE risk stratification system in the current era: how accurate is it 
and what should be done if it is inaccurate? Eur J Cardiothorac Surg 2009; 35:59-61.

[13] Horan TC, Gaynes RP, Martone WJ, Jarvis WR, Emori TG. CDC definitions of nosocomial surgical site infections, 1992: a modification of CDC definitions of surgical wound infections. Am J Infect Control 1992;20:271-4.

[14] Nagachinta T, Stephens M, Reitz B, Polk BF. Risk factors for surgical-wound infection following cardiac surgery. J Infect Dis 1987;156:967-73.

[15] Lee YP, Feng MC, Wu LC, Chen SH, Chen YH, Chiu CC et al. Outcome and risk factors associated with surgical site infections after cardiac surgery in a Taiwan medical center. J Microbiol Immunol Infect 2010;43:378-85.

[16] Berg TC, Kjorstad KE, Akselsen PE, Seim BE, Løwer HL, Stenvik MN et al. National surveillance of surgical site infections after coronary artery bypass grafting in Norway: incidence and risk factors. Eur J Cardiothorac Surg 2011;40:1291-7.

[17] Leal-Noval SR, Marquez-Vacaro JA, Garcia-Curiel A, Camacho-Laraña $P$, Rincón-Ferrari MD, Ordoñez-Fernández A et al. Nosocomial pneumonia in patients undergoing heart surgery. Crit Care Med 2000;28:935-40.

[18] Kollef MH, Sharpless L, Vlasnik J, Pasque C, Murphy D, Fraser VJ. The impact of nosocomial infections on patient outcomes following cardiac surgery. Chest 1997;112:666-75.

[19] Salis S, Mazzanti VV, Merli G, Salvi L, Tedesco CC, Veglia F et al. Cardiopulmonary bypass duration is an independent predictor of morbidity and mortality after cardiac surgery.J Cardiothorac Vasc Anesth 2008;22:814-22.

[20] Hill GE, Frawley WH, Griffith KE, Forestner JE, Minei JP. Allogeneic blood transfusion increases the risk of postoperative bacterial infection: a meta-analysis. J Trauma 2003;54:908-14.

[21] Leal-Noval SR, Munoz-Gomez M, Arellano V, Adsuar A, JiménezSánchez M, Corcia $Y$ et al. Influence of red blood cell transfusion on CD4+ T-helper cells immune response in patients undergoing cardiac surgery. J Surg Res 2010;164:43-9.

[22] Vamvakas EC, Blajchman MA. Transfusion-related immunomodulation (TRIM): an update. Blood Rev 2007;21:327-48.

[23] Titlestad IL, Ebbesen LS, Ainsworth AP, Lillevang ST, Qvist N, Georgsen J. Leukocyte-depletion of blood components does not significantly reduce the risk of infectious complications. Results of a double-blinded, randomized study. Int J Colorectal Dis 2001;16:147-53.

[24] Sharma AD, Slaughter TF, Clements FM, Sreeram G, Newman MF, Phillips-Bute $B$ et al. Association of leukocyte-depleted blood transfusions with infectious complications after cardiac surgery. Surg Infect (Larchmt) 2002;3:127-33.

[25] Bilgin YM, van de Watering LM, Eijsman L, Versteegh MI, van Oers MH, Brand $\mathrm{A}$. Is increased mortality associated with post-operative infections after leukocytes containing red blood cell transfusions in cardiac surgery? An extended analysis. Transfus Med 2007;17:304-11.

eComment re: The role of patient's profile and allogeneic blood transfusion in development of post-cardiac surgery infections: a retrospective study

\section{Authors: Leo A. Bockeria and Dmitry A. Popov}

Bakoulev Scientific Center for Cardiovascular Surgery, Moscow, Russia doi: 10.1093/icvts/ivu180

(c) The Author 2014. Published by Oxford University Press on behalf of the European Association for Cardio-Thoracic Surgery. All rights reserved.
We have read the article by Vranken et al. [1] with great interest. Using their large clinical experience (7888 adult patients mainly undergoing coronary artery bypass grafting (CABG) and CABG + valvular surgery), the authors studied the incidence of infectious complications after cardiac surgery and the importance of blood product transfusion as one of risk factors for their development.

Postoperative infection remains a problem in modern cardiac surgery, regardless of improvements in surgical technique and antibacterial prophylaxis. Its development cannot be explained only by failures in aseptic and antiseptic protocols during interventions. Compromised splanchnic perfusion and tissue ischaemia commonly observed during cardiopulmonary bypass (CPB) can lead to decrease of mucosal barrier function, allowing translocation of intestinal flora and endotoxaemia which can promote the development of infectious complications [2]. Therefore it is not surprising that infection after surgery with CPB is not a rare phenomenon - an infectious complication rate of up to $12 \%$ is reported in the current study. It would have been better if the authors had described the criteria for infection more precisely. For instance, body temperature of $37.5^{\circ} \mathrm{C}$ and pulmonary acoustics are not accurate for pneumonia; the use of CPIS score would be more specific. So, at least, the rate of pneumonia might be overestimated. The simple integral marker of body ischaemia is blood lactate level. High lactate levels early postoperatively are strongly associated with complications and poor outcome. Taking into consideration the above mentioned pathogenetic features we suggest that it would be very important to assess blood lactate levels in connection with infection.

Typical victims of nosocomial infection are intensive care unit (ICU) patients. Patients staying in the ICU for more than a couple of days due to various non-infectious postoperative complications have a dramatically increased risk of infection. According to the EPIC II multicentre study (14414 patients were enrolled in 1265 ICUs in 76 European countries), the "normal" incidence of infection in ICU can reach $50 \%$ ! [3]. In this connection it would be interesting to investigate the importance of ICU length of stay in addition to the studied risk factors. Transfusion of blood and its products, despite their undoubted life-saving effects, can be harmful due to the wide spectrum of possible side effects and complications, including immune system disturbances and organ injury (particularly the lungs). Obviously, it may predispose to infection. From reading the article, the time of transfusion is not clear: whether it was intraoperatively/early postoperatively due to acute blood loss, or later for anaemia in critically ill patients staying in the ICU. We suggest that these groups should be studied separately due to their completely different underlying conditions.

Nevertheless, the article is very important for clinical practice, because it is postulating one more time two very important things: infectious complications after heart surgery are not rare and blood products must be used very carefully.

Conflict of interest: none declared.

\section{References}

[1] Vranken NP, Weerwind PW, Barenbrug PJ, Teerenstra S, Ganushchak YM, Maessen JG. The role of patient's profile and allogeneic blood transfusion in development of post-cardiac surgery infections: a retrospective study. Interact CardioVasc Thorac Surg 2014;19:232-8.

[2] Klein DJ, Briet F, Nisenbaum R, Romaschin AD, Mazer CD. Endotoxemia related to cardiopulmonary bypass is associated with increased risk of infection after cardiac surgery: a prospective observational study. Crit Care 2011;15:R69.

[3] Vincent JL, Rello J, Marshall J, Silva E, Anzueto A, Martin CD et al. International study of the prevalence and outcomes of infection in intensive care units. JAMA 2009;302:2323-9. 